Editorial

\title{
Resources 2019 Best Paper Awards
}

\author{
Resources Editorial Office
}

MDPI AG, St. Alban-Anlage 66, 4052 Basel, Switzerland; resources@mdpi.com

Received: 30 June 2020; Accepted: 7 July 2020; Published: 14 July 2020

Resources is instituting the Best Paper Awards to recognize the outstanding papers published in the journal. We are pleased to announce the Resources Best Paper Awards for 2019 in two categories, "Review Paper" and "Research Article". Nominations were chosen from all papers published in 2018. The selection committee-which consisted of Editorial Board Members and the Editor-in-Chief-examined each paper and expressed their ranking of top candidates for the Resources Best Paper Awards 2019.

The following top-voted review paper and research article have won the Resources Best Paper Awards for 2019, and a further research article was highly commended.

\section{Review Paper Award}

Global Lithium Sources-Industrial Use and Future in the Electric Vehicle Industry: A Review Laurence Kavanagh, Jerome Keohane, Guiomar Garcia Cabellos, Andrew Lloyd, John Cleary

Resources 2018, 7(3), 57; doi:10.3390/resources7030057

Available online: https://www.mdpi.com/2079-9276/7/3/57

The review paper on "Global Lithium Sources - Industrial Use and Future in the Electric Vehicle Industry" was an output of our project which established the baseline levels of lithium in soils, waters, and plants in the South-East of Ireland, prior to any future extraction of lithium from known pegmatite deposits in the Blackstairs Mountains.

Lithium is a key component in energy storage technologies and is rapidly becoming a metal of crucial importance. Increased demand for lithium as a component in batteries for electronic devices and electric vehicles is driving up the cost of lithium, with the result that previously uneconomic sources of lithium are being reassessed and some of these are likely to enter production. Indeed, lithium is expected to be added to the European Commission's list of critical raw materials later in 2020 because of its strategic importance to the automotive industry.

The paper focuses on lithium in the environment, the environmental effects of lithium extraction, various industrial uses of lithium and lithium recycling. Detailed information on historic and new lithium mineralizations is also presented. Finally, we discuss recent trends in demand and uses for lithium, with emphasis on the European Union and on the electric vehicle industry (Figure 1). 


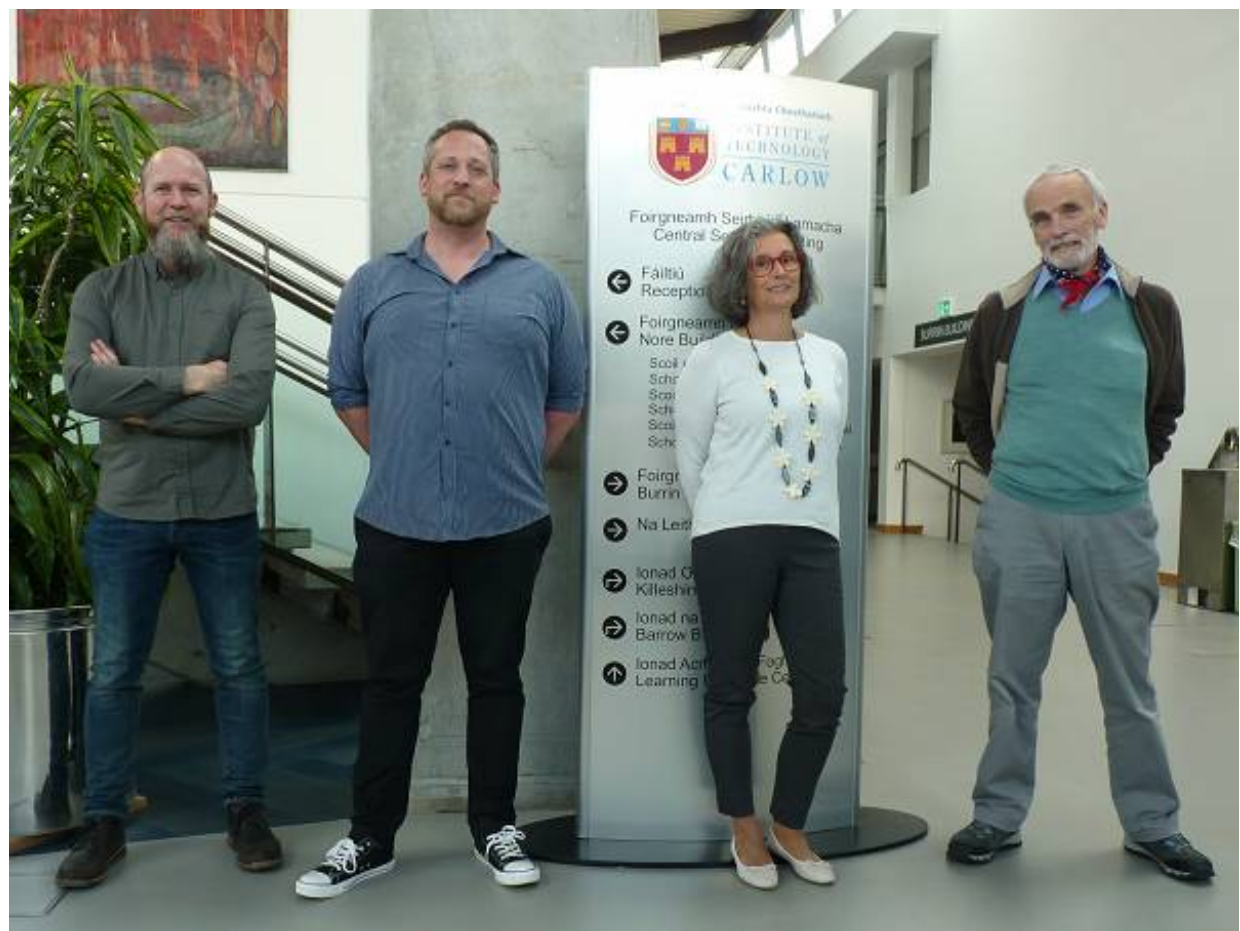

Figure 1. John Cleary, Laurence Kavanagh, Guiomar Garcia Cabellos and Andrew Lloyd (from left to right).

\section{Research Article Awards}

\subsection{The Winner of the Research Article Award Is:}

Implications of Emerging Vehicle Technologies on Rare Earth Supply and Demand in the United States

Tomer Fishman, Rupert J. Myers, Orlando Rios, T.E. Graedel

Resources 2018, 7(1), 9; doi:10.3390/resources7010009

Available online: https://www.mdpi.com/2079-9276/7/1/9

Emerging vehicle technologies employ large amounts of critical materials such as rare earths. Our study highlights the unprecedented future demands for different rare earth metals, such as neodymium and cerium, in the US transportation sector, driven by the adoption of new technologies in hybrid and electric cars. We explored the potential of novel aluminum-cerium alloys to replace traditional steel and aluminum and the consequent effects on rare earth primary and secondary supply in the green transport sector. Our scenarios suggest that the secondary rare earth supply from end-of-life vehicles could eventually prove to be more abundant than rare earths from traditional domestic mines in the United States, which presents a potential pathway to the reduction of rare earth metals' criticality (Figure 2).

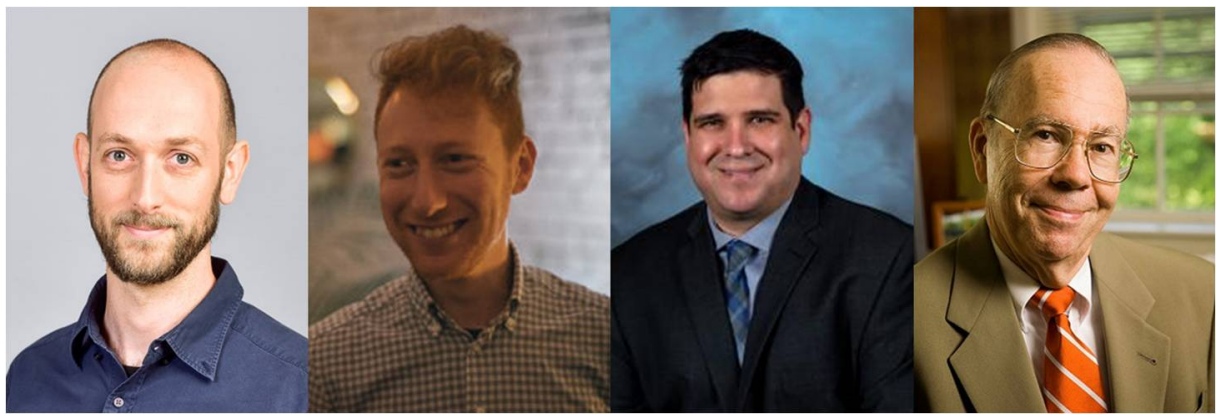

Figure 2. Tomer Fishman, Rupert J. Myers, Orlando Rios, T.E. Graedel. (From left to right). 


\subsection{The Winner of the Highly Commended Research Article Is:}

Developing Adequate Communication of Waste Footprints of Products for a Circular Economy-A Stakeholder Consultation

Rafael Laurenti, Michael Martin, Åsa Stenmarck

Resources 2018, 7(4), 78; doi:10.3390/resources7040078

Available online: https://www.mdpi.com/2079-9276/7/4/78

This article reported a small-scale survey $(\mathrm{N}=28)$ among stakeholders aimed at developing adequate communication of the product waste footprints (PWF) of consumer goods. Most of the respondents expressed that the guidelines described in the proposed PWF methodology are good enough to differentiate waste and by-products and define which material flow to account for. The respondents also expressed that the PWF concept would be primarily useful and/or needed for consumers and governments, as well as in the contexts of improving the environmental awareness of consumers, environmental policymaking, visualizing waste flows in a circular economy and improving resource efficiency in the industry, and it would be less useful/needed in a business-to-business context. Since its development in 2015, PWF has been successfully used by diverse stakeholder groups in Sweden, mostly to promote sustainable production and consumption across society. A notable example is the "invisible waste" campaign of the Swedish Waste Management Association. The symbolic power and parsimony of the PWF concept appear to be effective in sensitizing consumers about the need for a circular economy beyond recycling (Figure 3).

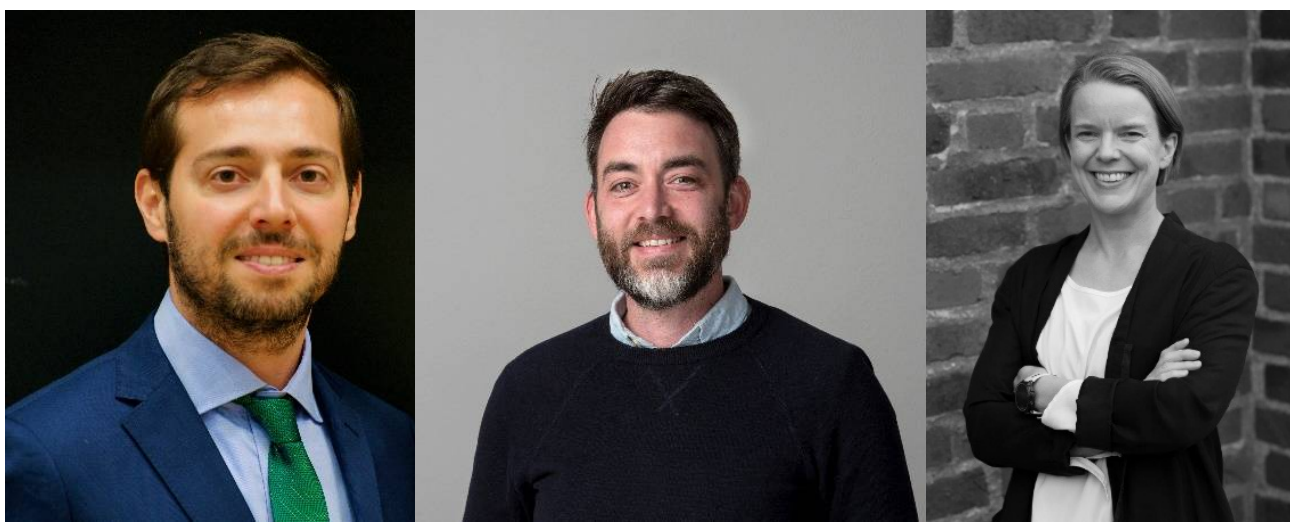

Figure 3. Rafael Laurenti, Michael Martin, Åsa Stenmarck (from left to right).

These three papers are all highly valuable contributions to Resources. On behalf of the Resources Editorial Board, we would like to congratulate these teams for their excellent work.

We would like to take this opportunity to thank all the authors of the above papers for their contributions to Resources, and we thank the Resources Editorial Board for voting and helping with the 2019 Best Paper Awards.

The Editorial Board and Editorial Staff at Resources are committed to meeting the needs of our research community by providing constructive and timely reviews of all quality manuscripts submitted and providing an open access journal for the broad dissemination of your findings. Please consider submitting your work to Resources, and we look forward to considering your paper as a Resources Best Paper in the future.

(C) 2020 by the author. Licensee MDPI, Basel, Switzerland. This article is an open access article distributed under the terms and conditions of the Creative Commons Attribution (CC BY) license (http://creativecommons.org/licenses/by/4.0/). 